\title{
Current state and prospects for the development of commercial aquaculture in the Central Federal District
}

\author{
Konstantin Tyupakov ${ }^{1}$, Grigory Voloshin² and Evgeny Akimov,** \\ ${ }^{1}$ Kuban State Agrarian University named after I.T. Trubilin, Krasnodar, 350044, Russia \\ ${ }^{2}$ Russian Federal Research Institute of Fisheries and Oceanography, Moscow, 107140, Russia
}

\begin{abstract}
The purpose of the study is to analyze the current state of aquaculture development in Russia (using the example of the Central Federal District). Priorities for the development of aquaculture were identified, as well as the main directions for solving the problems posed. These include the development of aquaculture through the introduction of new technologies for growing commercial fish, the most advanced forms of organizing production, the development of domestic fodder production, trout farming and sturgeon farming. The article predicts the development of commercial fish farming in the Central Federal District for 2024, taking into account the proposed changes in the technology of fish farming and the organization of production, based on further cooperation and integration. The accelerated development of aquaculture will ensure the production of high-quality and high-value fish species and create a stable basis for the formation of food security in the country.
\end{abstract}

\section{Introduction}

In Russia, a state policy is being implemented regarding the development of fisheries in inland waters, with aquaculture playing a special role. Active use of aquaculture opportunities allows the country to obtain sustainable additional resources to strengthen food security, as well as gain great weight and influence on the international scene as a supplier of animal products. As you know, the country's food security is determined by the ratio of resources to their needs. Currently, about $95 \%$ of the extracted resources in the fishing industry in Russia are in the open seas and oceans. The complexity of their formation depends on the distribution of international catch quotas in open waters, the degree of their use, foreign policy factors, etc.

In addition, the introduction of economic sanctions against Russia has led in recent years (2014-2018) to a decrease in imports of fish food products by $49.5 \%$, which has slowed the growth in per capita consumption of fish and fish products in the country. In 2018, it amounted to $20.7 \mathrm{~kg}$ versus $22 \mathrm{~kg}(94.1 \%)$ at the average annual per capita consumption rate recommended by the Ministry of Health of the Russian Federation [1]. The creation of a stable raw material base in Russia has its own economic advantages due to the accelerated development of aquaculture. Aquaculture as a managed economy is determined by independence from the raw materials base of oceanic and marine fisheries, lower energy and labor costs compared to open-water fishing, proximity to sales markets, and most importantly, the ability to ensure high quality products at any time of the year [7].

\section{Materials and methods}

The article uses statistical sources from the Federal State Statistics Service, materials from the Ministry of Agriculture of Russia, the Federal Agency for Fishery, the Association of the Federal Agency for Fishery, and also operational data on the work of fish farms in the Central Federal District located in different climatic zones. The forecast of the development of commercial fish farming based on the trend model (exponential function) until 2024 is made. Trends in the development of feed production based on the construction of feed workshops for the needs of trout farming and sturgeon breeding are identified, which will help reduce feed imports. Another important area is the elimination of the deficit of fish stock by reducing the area of growing ponds and transferring them to feeding ones.

\section{Results and Discussion}

Over the period under review (from 2010 to 2019), the volume of commercial fish farming in Russia increased by 2.1 times. The average annual growth rate was $5.6 \%$ (Figure 1).

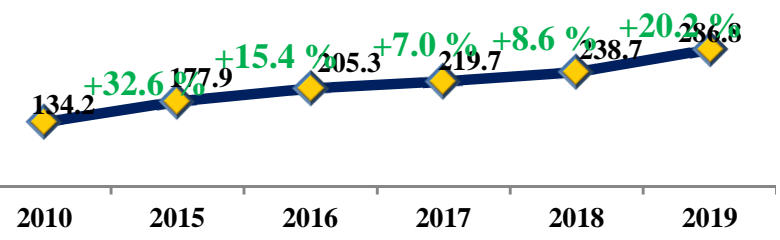

Fig. 1. Dynamics of the volume of Russian production of commercial fish products (including fish stocks) from 2010 to 2019, thousand tons

* Corresponding author: akimov@vniro.ru 
Moreover, commodity fish farming in Russia has received particularly accelerated development in recent years. If the average annual growth rate of commercial fish farming in 2010-2015 was $5.7 \%$, then in 2015-2019 it increased to $12.7 \%$. Significant growth in commercial fish farming was recorded over the past 3 years (from 2017 to 2019 ) is $130.5 \%$.

The basis of commodity fish farming in Russia is pond fish farming, which in 2018 accounted for $47 \%$ of the total production. The share of industrial and pasture (lake) fish farming in 2018 was 31 and $22.2 \%$ of the total volume of marketable fish, respectively. Currently, about 25 breeds, crosses and fish species are grown in Russia, as well as 9 domesticated forms of cyprinid, salmon, sturgeon, whitefish and cichlid fish in almost all regions of the country. The leaders in pond fish farming in the country are the Southern, Northwestern, Central, North Caucasian and Volga Federal Districts, which accounted for over $87.5 \%$ of the total production of the industry in 2018.

In accordance with the territorial features of the country, industrial fish farming is located in 6 geographical zones, differing in natural and climatic conditions [2]. Commodity fish farming of the Central Federal District (CFD) is carried out in the territory of zones $1-4$, where, in contrast to the southern 5-6 zones, climatic conditions are less favorable. Nevertheless, large reserves have been laid here for the accelerated development of commodity fish farming.

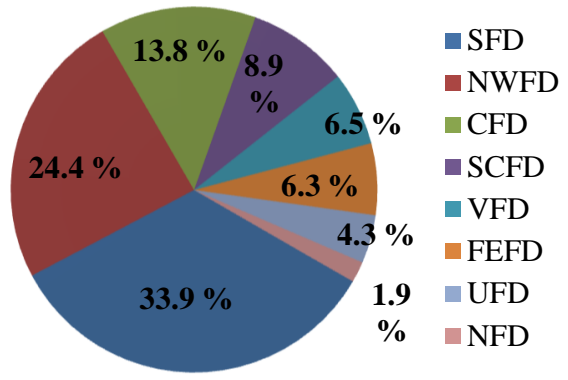

Fig. 2. Shares of the Federal Districts for the production of commercial fish for 2018

From 2010 to 2018, the volume of commercial fish farming in the Central Federal District increased by 17.6 $\%$ and amounted to 28 thousand tons at the end of 2018 . The Central Federal District accounts for about $13.8 \%$ of the total volume of Russian commercial aquaculture products (Figure 2). However, the share of the Central Federal District in the total production of commercial fish in Russia decreased from $19.7 \%$ in 2010 to $13.8 \%$ in 2018. The main reason is associated with a decrease in the production of commercial fish in Voronezh (by $36.4 \%$ ), Tambov (by $40 \%$ ), Vladimirskaya (by $10.1 \%$ ) and Tula (by $87.5 \%$ ) regions. The main objects of commodity cultivation in 2018 in the Central Federal District are carp (20.8 thousand tons), trout (1.8 thousand tons), sturgeon (1.4 thousand tons) and herbivorous fish species (2.7 thousand tons) (Figure 3 ). Main producers of silver carp, grass carp, trout, pike, sturgeon are OJSC "Biserovsky fish factory", CJSC SHP "Lipetskrybkhoz", JSC "Smolenskrybkhoz", OJSC
"Volgorechenskrybkhoz", OJSC "Ryazanrybprom”, JSC "Egorievsky fish factory", JSC "RybkhozKlinsky" and others that produce more than 20 thousand tons of salable fish.

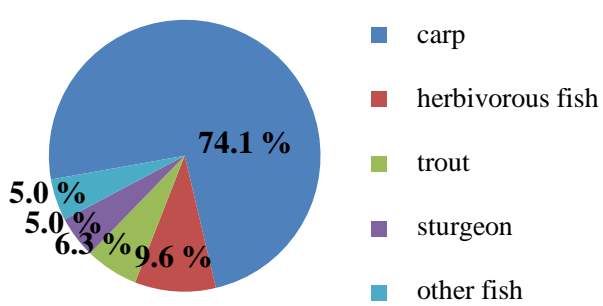

Fig. 3. The main objects of commodity cultivation in the Central Federal District in 2018

According to the results from 2010 to 2018, the most accelerated growth was observed in Belgorod (144\%), Kursk (131.3 \%), Voronezh (131.9\%), Lipetsk $(132.9 \%)$, Kaluga $(156.9 \%)$, i.e. in areas in the most favorable climatic conditions of production, as well as in the areas of Tver $(129.1 \%)$, Moscow (154.8\%) with 60 - 75 days in excess of $150 \mathrm{C}$. These regions currently account for $85.9 \%$ of the total cultivation of marketable fish in the Central Federal District. The development of marketable fish farming is developing in the following areas: pond, pasture aquaculture in lakes and reservoirs.

A large reserve for increasing the production of marketable fish in pond fish farming is the use of a polyculture of fish (carp with herbivorous fish).
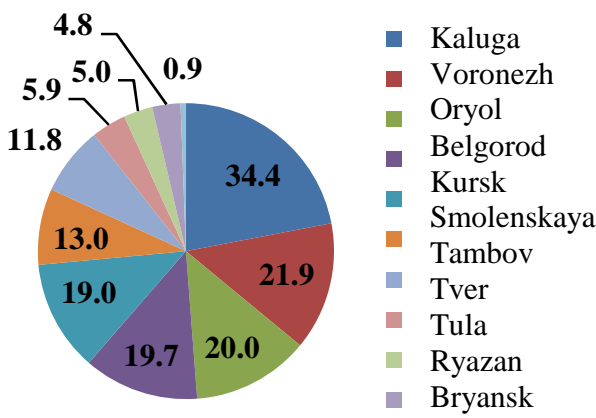

Fig. 4. The share of cultivation of herbivorous fish species by region of the Central Federal District in 2018

As can be seen from Figure 4, the proportion of herbivorous fish (Tverskaya, Tula, Ryazan, Bryansk) is still low and ranges from $0.9-6 \%$. This is due to the fact that in these areas the specialization of commercial fish was previously oriented mainly to carp or valuable fish species (sturgeon, trout). Therefore, the fish farms of these regions grow small volumes of herbivorous fish in the total volume of fish grown. The share of herbivorous fish in total catches, according to V.K. Vinogradov [3] should be: zones 1 and 2-20 \%, zones 3 and $4-30-40 \%$. According to the authors, bringing the recommendations to the indicated ratios when growing herbivorous fish species will make it possible to additionally obtain about 
6 thousand tons of pond fish in the Central Federal District.

The development of the industrial direction of commercial fish farming in the Central Federal District is associated with the cultivation of especially valuable fish species (trout, sturgeon, whitefish, clarisom, etc.), which is carried out in facilities with a closed water supply system, as well as in fish breeding areas using cages and pools.

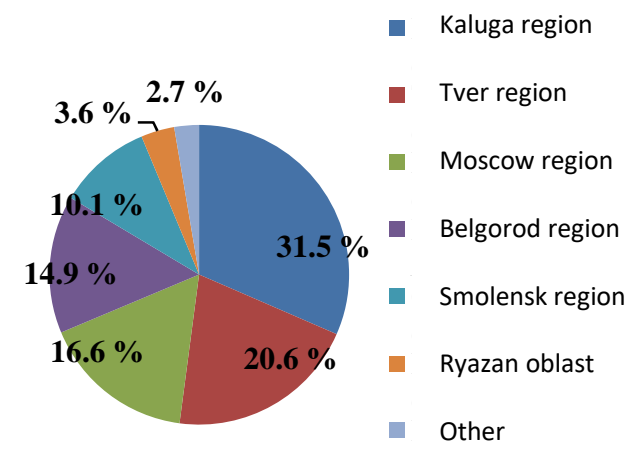

Fig. 5. The share of trout cultivation in industrial fish farming by region in the Central Federal District in 2018

The industrial direction should be considered as the most important reserve for growth in the long term of production volumes of commercial fish farming by cultivating the most valuable fish species and increasing production efficiency. The data from Figure 5 indicate a low share of trout farming (with the exception of the Kaluga region) .In 2018, out of 17 regions of the Central Federal District, only 9 regions were engaged in trout farming in cages and basins, where 1.7 thousand tons were grown.

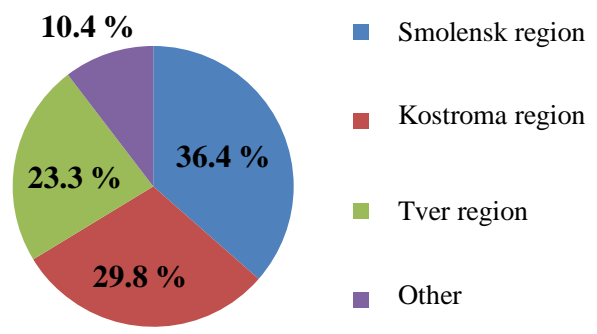

Fig. 6. The share of sturgeon fish species in industrial fish farming by region in the Central Federal District in 2018

A somewhat different situation is observed with the cultivation of sturgeon species. Only in 4 regions (Smolensk, Kostroma, Tver, Yaroslavl) is sturgeon cultivation specialized. In 2018, only 1.4 thousand tons of sturgeon fish were grown in these areas (Fig. 6). The development of sturgeon breeding and trout farming in other areas of the Central Federal District will make it possible to bring their volume to 4.5-5.0 thousand tons by 2024 , due to the accelerated development of industrial fish farming.
The difference in growth rates of salable fish cultivation by fish breeding zones was due not only to the influence of climatic conditions on the results of industrial and economic activities of fish farms, but also, above all, different biological, technological and organizational and technical features of production. The latter significantly influenced the final results of the work of fish farms [8] (Table 1)

Table 1. Economic indicators of fish farms in the climatic zones of the Central Federal District for 2018

\begin{tabular}{|l|c|c|c|c|c|}
\hline \multirow{2}{*}{ Index } & \multicolumn{4}{|c|}{ Climate zone } & Total \\
\cline { 2 - 5 } & $\mathbf{1}$ & $\mathbf{2}$ & $\mathbf{3}$ & $\mathbf{4}$ & \\
\hline The number of farms in \% & 31.3 & 27.5 & 18.8 & 22.6 & 100.0 \\
\hline $\begin{array}{l}\text { Commodity fish } \\
\text { production, \% }\end{array}$ & 23.1 & 18.7 & 24.1 & 34.1 & 100.0 \\
\hline Production of fish stock, \% & 17.6 & 18.8 & 27.9 & 35.7 & 100.0 \\
\hline $\begin{array}{l}\text { Fish productivity of feeding } \\
\text { ponds, t / ha }\end{array}$ & 8.7 & 8.6 & 9.6 & 14.0 & 10.1 \\
\hline $\begin{array}{l}\text { Cost of 1 ton, thousand } \\
\text { rubles }\end{array}$ & 179.0 & 145.6 & 187.5 & 266.1 & 778.2 \\
\hline Profit, million rubles & 19.8 & 15.4 & 19.9 & 27.4 & 82.5 \\
\hline $\begin{array}{l}\text { Profitability of production } \\
\%\end{array}$ & 9.9 & 9.6 & 9.1 & 9.3 & 9.2 \\
\hline $\begin{array}{l}\text { Volume of production, } \\
\text { million rubles }\end{array}$ & 198.8 & 161.0 & 207.4 & 293.5 & 860.7 \\
\hline $\begin{array}{l}\text { The average selling price of } \\
\text { t ton of fish, thousand } \\
\text { rubles }\end{array}$ & 250.4 & 296.2 & 178.4 & 202.5 & 231.8 \\
\hline
\end{tabular}

As it can be seen from the data in Table 1, in 2018, $58.8 \%$ of farms located in climate zones 1 and 2 produced $41.8 \%$ of the total volume of fish growing. The bulk of the production of $58.2 \%$ was observed in the southern regions located in climatic zones 3 and 4, where fish productivity was $1.5-2$ times higher than in the northwestern regions.

However, the profitability of production in all zones was approximately the same $(9.1-9.9 \%)$ and the main reason, first of all, was the difference in the structure of catches. In the structure of catches of fish farms located in zones 1 and 2, high-value fish species (24 trout and sturgeon), while in the catches of fisheries of zones 3 and 4 , the share of these fish species amounted to a little more than $6 \%$. This, ultimately, was reflected in the average selling prices of salable fish: 214.3 rubles per $\mathrm{kg}$ of fish in zones 1 and 2, and 116 rubles per $\mathrm{kg}$ in 3 and 4 zones, which naturally slowed down the negative impact of natural and climatic conditions on the results work of fish farms located in zones 1 and 2.

This gives reason to believe that further growth in the production of fish farms, especially for the Southern zone, should come from the intensive cultivation of high-value fish species (trout, sturgeon) in cages and pools. More than 250 pond fish- with a total pond area of about 25 thousand hectare are concentrated in the Central Federal District. About $75 \%$ of them are small farms, the annual volume of fish production, which does not exceed 100 tons per year, and the sales volume does not exceed 20 million rubles a year. Fish-producing organizations average in production capacity (10002000 tons of products per year) make up $22.4 \%$, with an annual sales volume of 90-180 million rubles. Large fish 
farms focused on selling over 2500 tons of products per year receive over 400 million rubles of cash proceeds [4].

Organizational - economic level of concentration of production prevailing in certain areas of the Central Federal District, due to the uneven distribution, development and effectiveness of commercial fish farming for individual fish farms [5]. About $70 \%$ of pond fish farms are concentrated in the southern regions, such as Belgorod (67 farms), Kursk (53 farms), Voronezh (31 farms), Kaluga (54 farms), Lipetsk (7 farms) and Ryazan (38 farms). In the considered regions and, accordingly, in $1-4$ zones of commercial fish farming, a combination of the 2 - and 3 - year fish rearing cycle is used. Moreover, if earlier in 1-2 zones a 3 -year cycle of fish growing was mainly used, and in 34 zones a two-year one, then a 2-year or a combination of a 2- and 3-year growing cycle is currently used, which is associated with features of fish farming technologies.

An important factor is the technology of growing fish, which depends on the size of the farm and the prevailing methods of growing fish. The most advanced technology is the technology of continuous fish farming. The technology of continuous cultivation of commercial fish is used in certain areas in 3 and 4 fish farming zones (Lipetsk, Belgorod, Voronezh, etc.), and can also be used in 1 and 2 fish farming zones.

The effectiveness of such cultivation consists, first of all, in shortening the production cycle as a result of reducing transplantation from the pond to the pond (excluding spawning), which extends the period of fish growth by $1-1.5$ months. The introduction of continuous technology, with the existing structure of production capacities, can significantly reduce the material and energy consumption of products, save water consumption for growing $1 \mathrm{~kg}$ of fish by 3 to 5 times, reduce the costs of bred juveniles by $1 \mathrm{~kg}$ of marketable products by 2 times, and by $35-40 \%$ reduce the cost of $1 \mathrm{~kg}$ of salable fish. Thus, the use of continuous technology of fish farming can be an effective alternative to traditional (basic) technology.

The spread of continuous technology in zones 1-4 of the Central Federal District sharply raises the question of the ratio of the 3-year and 2-year cycle of fish rearing, as well as the share of herbivorous fish in the total catch. According to V.I. Kozlova [6] the optimal percentage of fish rearing at two-year and three-year turnover should be in the range of 70-30\% (in zones $1-2$ ), and 40-60 $\%$ (in 3-4 zones). An important role in ensuring the development of commercial fish farming in the Central Federal District is played by the production of fish seed material. Practice shows that with an increase in the piece weight of fish seed material $(100-150 \mathrm{~g})$, a twoyear cycle of fish cultivation can be successfully developed in $1-2$ zones of fish farming. In this case, there is no need to use a 3-year cycle of growing commercial fish.

Fisheries that pay special attention to the production of fry are steadily increasing production and sales of fish, since the piece weight of the underyearlings significantly affects survival and planting density, which increases the fish productivity of feeding ponds. Despite the increase in the production of fish planting material in the farms of the Central Federal District, its implementation in 2018 decreased by 365 tons, which suggests that large farms that are able to produce and sell fry and fingerlings seek to reduce the area of ores and transfer them to feeding in order to obtain more final products.

Thus, fish farms of Belgorod, Vladimir, Kaluga, Moscow and Tver regions, with an increase in the production of fish seed material, reduced its sales, which contributed to an increase in the production (cultivation) of marketable fish. In farms where the production of fish planting stock is low due to its shortage, the production of marketable fish is small. Thus, there is a shortage of fish planting material in the region, which can be covered by creating a network of hatcheries, strengthening the vertical structure of interaction and cooperation of pedigree farms with commodity fish farms, as well as government incentives for the production and sale of fish stock.

A fundamentally important issue is the provision of pond farms with high-quality compound feeds especially for the needs of trout farming and sturgeon farming. Currently, the Central Federal District has a sufficient number of feed mills producing animal feed for agriculture (cattle, poultry, etc.). The production of feed for salmon, sturgeon and cyprinid fish species is carried out by the factories of OJSC "Aquarex" (Tver), LLC "LimKorm" (Belgorod region, city of Schebekino), which are not able to satisfy the demand of all fish farms in the region due to limited capacities and high prices.

The use of feed production plants producing extruded feed directly on farms can significantly reduce feed costs, differentiate them depending on the breed and age of the fish, as well as ensure the need for feed fish Region of the region. Reducing feed costs in the fish farm by an average of $25-30 \%$ will make it possible to get an additional effect of 4 million rubles / $\mathrm{t}$ annually, and the payback of a feed mill with a productivity of 500 tons / year will be about 5 years.

The authors performed calculations to determine the need for feed for the needs of trout farming and sturgeon breeding in the Central Federal District for 2024 for growing in cages and pools. With the growth of trout and sturgeon in 2024 to 4.5 thousand tons compared to 3.1 thousand tons in 2018 , or by $45.2 \%$, the need for feed for the cultivation of these species of fish, respectively, will increase from 3.2 to 4.9 thousand tons, i.e. by 53.1 $\%$ [9].

Based on the above areas, the authors made a forecast for the development of aquaculture (commercial fish farming) for 2024 based on the trend model (exponential function) (Figure 7). The forecast data indicate that, with an average annual growth rate of $5 \%$, the volume of aquaculture of commercial fish farming (including fish stock) in the Central Federal District it will increase from 37.8 thousand tons in 2018 to 50.7 thousand tons in 2024, or by $34.1 \%$, which will contribute to an increase in the average annual per capita consumption of marketable fish product [10]. 


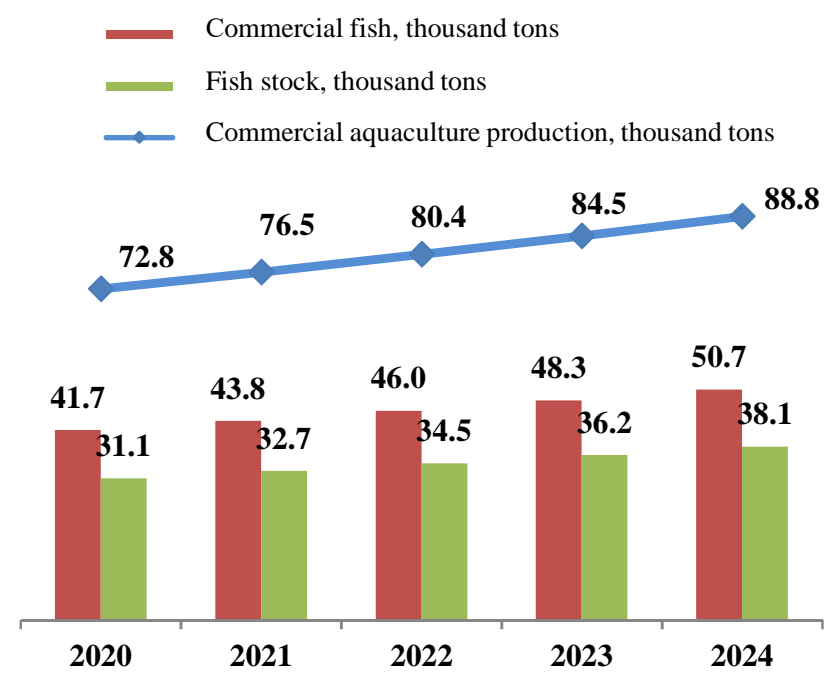

Fig. 7. Trend models of commodity aquaculture indicators in the Central Federal District

\section{Conclusion}

Currently, commercial fish farming in the Central Federal District (CFD) for a number of objective reasons (including natural and climatic ones) significantly lags in development behind other federal districts of Russia. Nevertheless, there are great potential opportunities, the implementation of which will allow in the future (until 2024) to increase by $34 \%$ (compared to 2018) the cultivation of marketable fish.

The analysis in certain regions showed that the main object of cultivation in most fish farms is pond carp, which account for more than $70 \%$ of the production of salable fish. Still poorly used are the technologies for growing pond fish in polyculture with carp. An increase in its share from $18-19 \%$ at present to $35 \%$ in the regions of the Central Federal District would make it possible to increase the fish productivity of ponds due to growth (silver carp, grass carp, etc.) by 2 times, and additionally receive about 6 thousand tons of pond fish. On the other hand, the production of valuable fish species (trout and sturgeon) due to the accelerated development of the industrial sector will make it possible in the near future to increase the volume to 4.5-5.0 thousand t., which will help increase the economic efficiency of commercial fish farming.

Another reason for the lag in the development of commercial fish farming in the Central Federal District is a break in production links between pond fish farming enterprises and the feed mill industry. It seems appropriate, due to state support, to expand the construction of mini - plants (workshops) in pond farms for the production of extruded and expanded feed. The experience of using such mini-factories (workshops) shows their high efficiency (3-3.5 year service life), which will allow them to abandon the import of feed, which is currently 35-40\% higher than the domestic price and save 900 million rubles.

\section{References}

1. Recommendations on rational food consumption standards that meet modern requirements for a healthy diet, approved by order of the Ministry of Health of the Russian Federation 19.08.2016 no. 614

2. Development of an updated forecast for the socioeconomic development of the fisheries of the Russian Federation from 2020-2024, Report of the All-Russian Research Institute of Fisheries and Oceanography on the theme (2019), 42 p.

3. Vladimir Konstantinovich Vinogradov, Materials for the bibliography (FGUP "VNIIPRH", Moscow, 2007), 55 p.

4. K.E. Tyupakov, YU.I. Bershickij, E.B. Akimov, Economic aspects of formation and development of pond fish farming in the Central Federal District, in: Collection of scientific works of 6th All-Russ. Sci. and pract. Conf. Issues and prospects of social and economic development of Southern Russia (Adygei State University) (ElIT publishing house, Majkop, 2020), 178 p.

5. G.A. Voloshin, E.B. Akimov, To the question of the optimal size of pond farms / Actual problems in modern science: theory and practice, Coll. of papers (Megapolis, Moscow, 2018), 57 p.

6. V.I. Kozlov, A.V. Kozlov, A textbook on commercial fish farming: economic solutions (Rosinformagrotekh, Moscow, 2017), 131 p.

7. H.M. Harliantara, M.L. Bandaso, P.P. Roreng et al., Sustainability of economic resources, J. of Environmental Treatment Techniques 8(1), 556-559 (2020)

8. N.A. Prodanova, L.B. Trofimova, A.A. Adamenko et al., Methodology for assessing control in the formation of financial statements of a consolidated business, Int. J. of Recent Technol. and Engineer. 8(1), 2696-2702 (2019)

9. O.Y. Voronkova, E.G. Perepechkina, R.A. Shichiyakh et al., Ecological and economic potential and prospects for organic production in the regions of Russia, Int. J. of Econ. and Busin. Administrat. 7(S1), 583-594 (2019)

10. S.M. Pozdyaeva, E.S. Gasanov, R.R. Yarullin et al., Justification of the market model in the modern Russian economic discourse: dialogue-monologue, Amazonia Investiga 8(22), 394-400 (2019) 